\title{
Nanostructured Surface Layer of Ti-4AI-2V by Means of High Energy Shot Peening
}

\author{
J. HAN, ${ }^{11}$ G. M. SHENG ${ }^{1,2)}$ and G. X. HU ${ }^{11}$ \\ 1) College of Materials Science \& Engineering, Chongqing University, Chongqing 400044, P. R. China. \\ E-mail: han.jing02@163.com $\quad$ 2) College of Materials Science \& Engineering, Chongqing University, Chongqing 400044, \\ P. R. China. E-mail: gmsheng@cqu.edu.cn
}

(Received on September 21, 2007; accepted on December 11, 2007)

\begin{abstract}
A nanostructured surface layer was formed on the ends of TA17 bars by means of high energy shot peening (HESP). Microstructures in the plastic deformation layer were systematically characterized and analyzed by using optical microscopy (OM), scanning electron microscopy (SEM), transmission electron microscopy (TEM), microhardness measurement and X-ray diffraction (XRD). Based on the experimental observations and analysis, nanograins with an average size of $35 \pm 5 \mathrm{~nm}$ were achieved on the top surface layer, the microhardness on the top surface is near twice that of the coarse-grained matrix. In terms of special metals materials, the stress and strain rate are critical for grain refinement in the process of surface self-nanocrystallization (SSNC). On the basis of discussion for microstructure in the plastic deformation layer, the grain subdivision mechanism of TA17 was drawn that twinning deformation transformed coarse grains into fine twinning lamellae at the low strain rate level, and the submicronic grains are broken down into randomly oriented nanograins by means of dislocation glide at high level of strain.
\end{abstract}

KEY WORDS: TA17; surface self-nanocrystallization (SSNC); high energy shot peening (HESP); twinning deformation; dislocation glide.

\section{Introduction}

Nanocrystalline (nc) materials refer to those materials which are structurally characterized by grains with size less than $100 \mathrm{~nm}$. The nc materials with a large number of grain boundaries have been found to exhibit many novel properties relative to their coarse-grained counterparts, such as high strength and hardness, good superplasticity at low temperature, ${ }^{1,2)}$ enhanced atomic diffusivities, ${ }^{3)}$ and unique properties of light, electricity and magnetism. Therefore, nowadays the research efforts of nano-materials are still attractive for material scientists on the world.

As for synthesizing of bulk nc materials, since the pioneering study of preparing bulk nc metals by means of metal gas condensation and consolidation by H. Gleiter ${ }^{4)}$ in the early 1980 s, various processing routes, such as the consolidation of ultrafine metals powders, the crystallization of amorphous precursors, ${ }^{5)}$ depositions ${ }^{6)}$ and severe plastic deformation of bulk matals, ${ }^{7}$ have been developed to synthesis bulk nc materials. However, in terms of above-mentioned techniques, two major obstacles still impede the development of bulk nc materials: (i) it is difficult to manufacture porosity-free and contamination-free samples, (ii) most of the techniques are not adapted to production on an industrial scale because of limitations of sample size. In recent years, an alternative approach ${ }^{8)}$ to synthesis of a nanostructured surface layer is to transform the original coarsegrained surface layer of a bulk material into nano-sized grains by different loading styles while keeping the overall composition and/or phase unchanged. Such a process may be referred as surface self-nanocrystallization (SSNC) of bulk materials. By using the SSNC process, original coarsegrains on many bulk metals surface layer have been successfully transformed into nano-sized grains and prepared nanostructured surface layer. ${ }^{9-16)}$ Comparing with others, the SSNC has some unique advantages, for example that the chemical compositions is unchanged in the nc surface layer and the matrix, the grain dimension exhibits a gradient variation from the top surface layer to coarse-grained matrix, bonding of the nc surface layer with matrix will not be a problem, there were porosity-free and contaminationfree in the nc structure layer of samples.

It is widely recognized that titanium and titanium alloy display low density, high specific strength, rich corrosion resistance, the quality of high temperature strength and low temperature ductility as well as good biologic solubility. As a result, extended applications which demand high levels of reliable performance can be anticipated in surgery and medicine as well as in the aerospace, automotive, chemical plant, power generation and other major industries. Therefore researching the surface self-nanocrystalliztion of titanium alloy and enhancing their over-all properties are very vital. In the work, the surface self-nanocrystalliztion of TA17 near $\alpha$ titanium alloy by means of HESP was systematically researched. 


\section{Experiment}

\subsection{Experimental Material}

Three TA17 near $\alpha$ titanium alloy bars $(\Phi 12 \times 3 \mathrm{~mm})$ with the following chemical composition (wt\%): $0.010 \mathrm{C}$, $0.040 \mathrm{Si}, 0.069 \mathrm{Fe}, 0.023 \mathrm{~N}, 0.003 \mathrm{H}, 4.500 \mathrm{Al}, 2.200 \mathrm{~V}$, $0.050 \mathrm{O}$ and rest $\mathrm{Ti}$ were subjected to the high HESP in order to achieve a nanostructured surface layer. Prior to the treatment, samples were annealed at $1023 \mathrm{~K}$ for $3 \mathrm{~h}$ in a vacuum furnace diminishing the effect of mechanical processing and obtaining homogeneous coarse equiaxial $\alpha$ grains $(20-50 \mu \mathrm{m})$, and there are a small amount $\beta$ phase between the boundaries. The end face was polished manually with silicon carbide papers to $1200^{\#}$ and then mechanically polished with $\mathrm{Al}_{2} \mathrm{O}_{3}$ polishing powder to achieve finish surface.

\subsection{Experimental Scheme}

Figure 1 shows a schematic illustration of the HESP treatment set-up used in the present work. Cast steel balls (shots) with $1 \mathrm{~mm}$ in diameter were threw with high velocity to the end face of the cylinder-shaped sample under peening pressure of about $0.6 \mathrm{MPa}$. Each peening of the ball to the surface will result in plastic deformation in the surface layer of the treated sample (as shown in Fig. 1(b)). As a consequence, repeated multidirectional peening at high strain rates on to the sample surface leads to severe plastic deformation in the surface layer. In this work, treatment time is a key parameter we controlled during experiment. In order to investigate effects of treatment time on characters of the SSNC layer, three kinds of treatment time were chosen for comparison experiment, namely $1 \mathrm{~min}$, $5 \mathrm{~min}$ and $13 \mathrm{~min}$ respectively. It was note that a restrain sleeve part with $12_{-0}^{+0.5} \mathrm{~mm}$ inner diameter was machined to grip the treatment end of sample and impeded metal on the peened surface to flow away rim of the surface (as shown in Fig. 1(a)). After the HESP treatment, the roughness of the surface increased significantly.

In order to research the structures evolution along the longitudinal-section, observations of the treated sample were performed on a OLYMPUS-GX41 optical microscope and a FEI NOVA NANOSEM 400 style scanning electron microscope.

The variations of microhardness with depth were measured on a longitudinal-sectional sample using a MICROHARDNESS TESTER HV-1000 fitted with a diamond indenter. The load for experiment was $0.98 \mathrm{~N}$, and loading time was $20 \mathrm{~s}$, The distance between any two neighboring indentations was $25 \mu \mathrm{m}$.

X-ray diffraction analysis of the surface layer in the HESP treated sample was performed on a D/Max-1200 X-ray diffractometer, with $\mathrm{Cu} K_{\alpha}$ radiation (wavelength $\lambda_{\alpha 1}=0.154056 \mathrm{~nm}, \lambda_{\alpha 2}$ was eliminated by a graphite monochromator using its (0002) reflection). Slit parameters of the diffractometer are $1^{\circ}-1^{\circ}-0.30 \mathrm{~mm}$.

Microstructure features on the top surface layer were characterized by using a Philip Tecnai 20 transmission electron microscope (operating at a voltage of $200 \mathrm{kV}$ ). Planeview thin foils for transmission electron microscope observations were prepared by means of cutting, grinding, dimpling and a final single-side ion-thinning at low tempera-

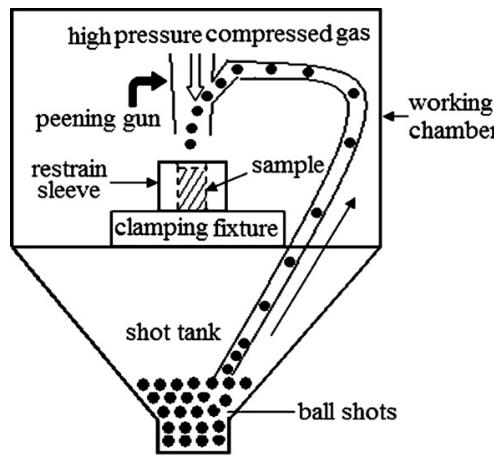

(a)

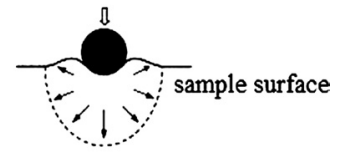

(b)
Fig. 1. The schematic illustration of the HESP treatment set-up (a) and the localized plastic deformation in surface layer by the peening of the shot (b).

tures. Plane-view thin foils were cut parallel to the treated surface (cross section), about $0.2 \mathrm{~mm}$ in thickness.

\section{Results}

\subsection{Optical Microscope Observations}

The longitudinal-section microstructures of specimens are shown in Fig. 2. On the whole longitudinal-section in the untreated sample, there are randomly oriented equiaxial coarse grains and no twins (as shown in Fig. 2(a)). However, a plastic deformation layer (as shown in Fig. 2(d)) with a great many of twins was produced in HESP samples treated for different time (1 $\mathrm{min}, 5 \mathrm{~min}$ and $13 \mathrm{~min}$ ), and the deformation layer thickness is about $230 \mu \mathrm{m}$. Severe plastic deformation was generated on the top surface layer of every treated sample because of high strain and stress, which resulted in formation of a severe plastic deformation layer (as shown in Fig. 2(d)), grain dimension and grain boundary in severe plastic deformation layer can not be distinguished by using optical microscope. But, thickness of the severe plastic deformation layer is raising with the increasing of treated time, the thickness is about $20 \mu \mathrm{m}$ in the sample treated for $1 \mathrm{~min}$ (as shown in Fig. 2(b)), ones of samples treated for $5 \mathrm{~min}$ and $13 \mathrm{~min}$ are about $80 \mu \mathrm{m}$ and $120 \mu \mathrm{m}$ respectively. A number of twins present to the area between matrix and severe plastic deformation layer, single-system twin is dominant near matrix, and multi-system twin is dominant close to a severe plastic deformation layer. The twin area became narrowing with the increasing of treated time (as shown in Figs. 2(b), 2(c) and 2(d)).

\subsection{Microhardness Distribution along the Depth of the Deformation Layer}

Figure 3 shows the variations of microhardness along longitudinal-section of treated samples. There is a obvious tendency that microhardness of treated samples rapidly reduce within $250 \mu \mathrm{m}$ from the treated surface, between $250 \mu \mathrm{m}$ and $500 \mu \mathrm{m}$, the variations of microhardness drive to gentleness. For the treated-13 min sample, the harden layer depth was arrived $600 \mu \mathrm{m}$, and the largest value of microhardness was reached $420 \mathrm{HV}_{100}$ that is nearly twice that of the matrix. For treated-13 min sample, the microhardness values is no obvious decrease after annealed at $673 \mathrm{~K}$ for $1 \mathrm{~h}$ for residual stress relaxation, which indicates 

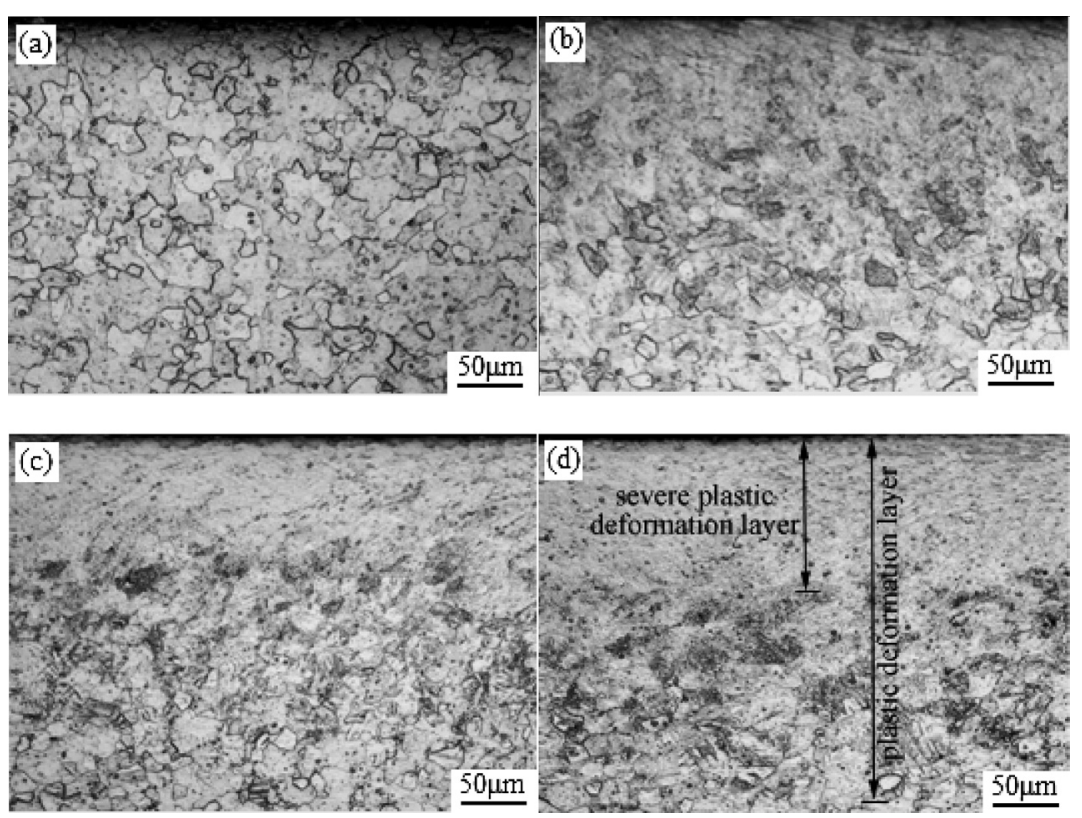

Fig. 2. Longitudinal-sectional OM micrographs of treated samples. (a) Annealed microstructure; (b) microstructure of sample treated for $1 \mathrm{~min}$; (c) microstructure of sample treated for $5 \mathrm{~min}$; (d) microstructure of sample treated for $13 \mathrm{~min}$.

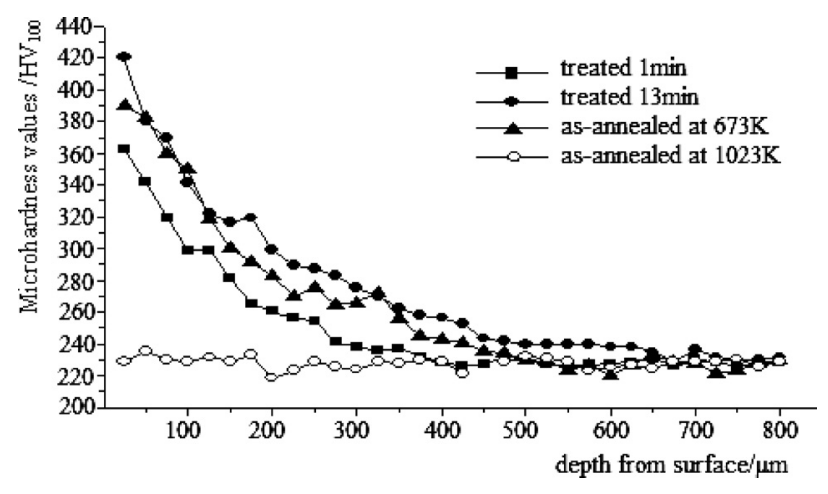

Fig. 3. Variation of microhardness along the depth from the treated surface of the HESP samples.

that the high hardness in the deformation layer is no resulted from the residual stress induced in the HESP. After annealed at $1023 \mathrm{~K}$ for $2 \mathrm{~h}$ for recrystallization of the nanostructures and formed coarse grains, the microhardness of the treated-13 min sample in the deformation layer drops to that of the coarse-grained matrix, the result indicates that the microhardness increment is due to grain refinement into the nanometer scale, in stead of the alloying (contamination) effect from the HESP media (balls and other impurities). The grain refinement can results in microhardness improvement according to Hall-Petch formula.

\subsection{X-ray Diffraction Analysis}

Figure 4 shows the X-ray diffraction (XRD) patterns of treated samples. It can be seen that the diffraction peaks widths are broadened with the increasing of HESP time, which implies that a great of defects were introduced into the samples and coarse grains were subdivided by means of HESP. The relative peak intensities of the treated samples are found to be comparable to the standard values of $\mathrm{Ti}$ in Joint Committee on Powder Diffraction Standards (JCPDS) cards, which indicates no texture was induced into the sam-

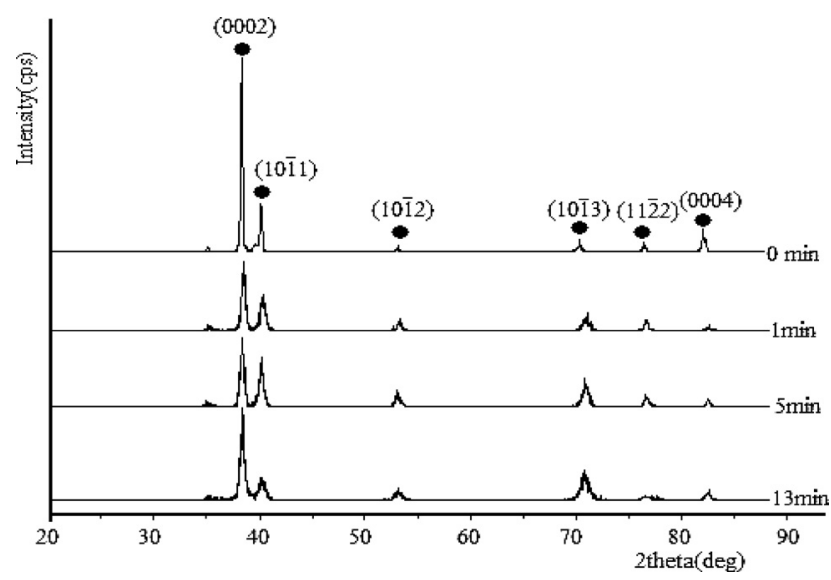

Fig. 4. XRD patterns of the surface layer of the HESP samples for different time.

ples during HESP.

Full Wave at Half Maximum (FWHM) of diffraction peaks were measured by the MDI Jade5.0 (a X-ray analysis software). The average grain size and mean microstrain were calculated from broadening of diffraction peaks, by using formula as follows:

$$
\frac{F W(s) \cdot \cos (\theta)}{\lambda}=\frac{K}{D}+4 \cdot \varepsilon \cdot \frac{\sin \theta}{\lambda}
$$

Where $F W(S)^{\mathrm{D}}=F W H M^{\mathrm{D}}-F W(I)^{\mathrm{D}}$ is $\mathrm{FWHM}$ of peaks after detracting broadening led by the diffractometer itself; $K$ is a constant, $K=0.89$ here; $\lambda$ is the wave length of the $\mathrm{Cu} K_{\alpha 1}$ irradiation; $\theta$ is Bragg diffraction angle; $D$ is mean grain size; $\varepsilon$ is mean lattice strain. By performing a least square fit $(F W(s) \cdot \cos (\theta)) / \lambda$ plotted against $(\sin \theta) / \lambda$ for all of the measured peaks of a sample, we are able to determine the mean grain size $D$ and the mean lattice strain $\varepsilon$. Result as shown Table 1. The results shown that the average grain size is $35 \pm 5 \mathrm{~nm}$, and mean microstrain from 
0.094 to $0.093 \%$ respectively, which showed that nanograins have been formed on the top surface and that grain sizes decreased with increase of treatment time.

\subsection{Scanning Electron Microscopy Observations}

Figure 5 is longitudinal-section SEM observations of sample treated for $13 \mathrm{~min}$. About $230 \mu \mathrm{m}$ below the treated surface, some coarse grains consist of parallel twin lamellae with widths varying from submicron to a few microns, and in different coarse grains, twin lamellae have different orientation (as shown in Fig. 5(a)). As the depth decreasing to about $150 \mu \mathrm{m}$ below the treated surface, at almost everywhere, single-system twinning deformation transformed most of coarse grains into very fine twin lamellae with

Table 1. The mean grain size and mean lattice strain of treated samples.

\begin{tabular}{ccc}
\hline treated time (minutes) & mean grain size $\mathrm{D}(\mathrm{nm})$ & mean lattice strain $\mathcal{E}(\%)$ \\
\hline 1 & 38.4 & 0.093 \\
5 & 33.3 & 0.087 \\
13 & 29.9 & 0.094 \\
\hline
\end{tabular}

width below $1 \mu \mathrm{m}$, in some places, multi-system twinning deformation converted original grains into submicron quadrilateral grids (as shown in Figs. 5(b) and 5(c)). With the reducing of the depth (about $80 \mu \mathrm{m}$ below treated surface), the fine lamellae structure has disappeared, and were subdivided into polygonal refined grains with below $400 \mathrm{~nm}$ by way of twin-intersection (as shown in Fig. 5(d)), at the zone, all coarse grains have been transformed into submicron grains with certain orientation. The Fig. 5 shows that twinning deformation is critical for refinement of coarse grains in the TA17 alloy, with the decreasing of depth to treated surface, single-system twinning deformation evolved into gradually multi-system twinning deformation, and the twin lamellae density became increasing with increment of strain and stress, about $80 \mu \mathrm{m}$ below treated surface, the coarse grains were transformed into submicron grains under durative high energy shot peening.

\subsection{Transmission Electron Microscopy Observations}

TEM observation about $50 \mu \mathrm{m}$ below the top treated surface of sample treated for $13 \mathrm{~min}$ shows that the microstructure differs considerably from twin microstructure observed above. The low angle disorientation subgrains with sizes of about $100 \mathrm{~nm}$ were formed by means of dislocations activity in submicron grains, as shown in Fig. 6(a),
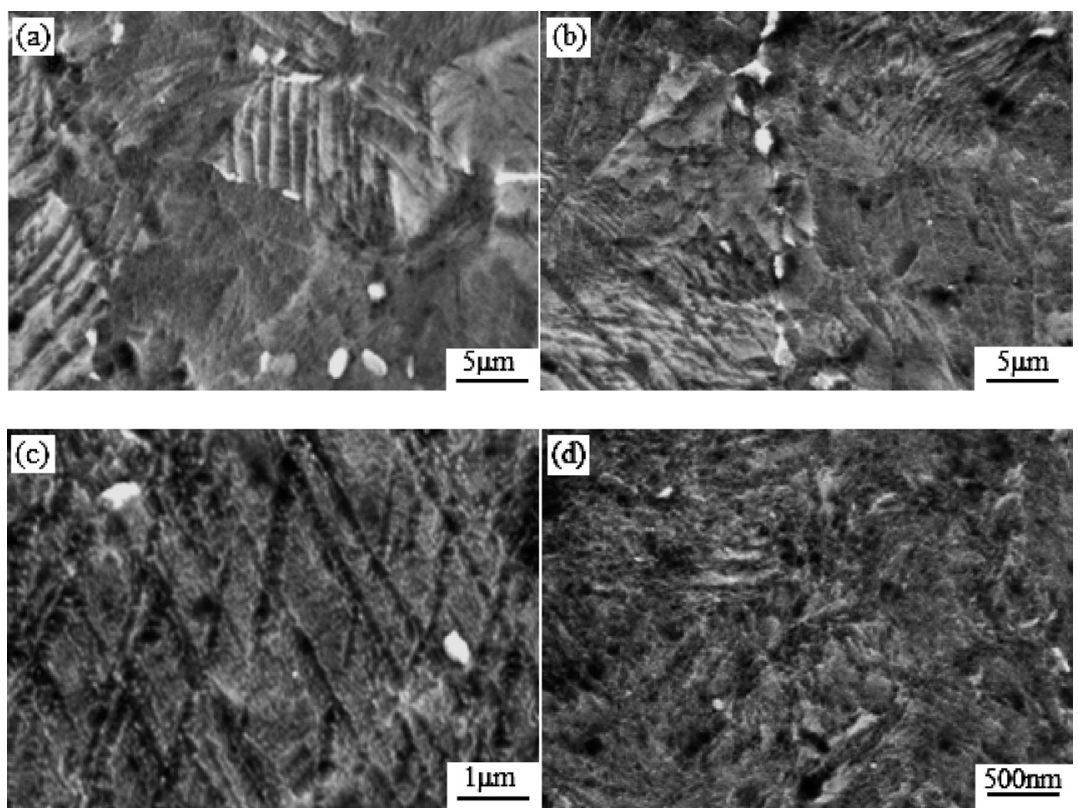

Fig. 5. SEM observation at different depth in the sample treated for 13 min. (a) SEM of sample about $230 \mu \mathrm{m}$ depth; (b) SEM of sample about $150 \mu \mathrm{m}$ depth; (c) intersection of twins in a grain; (d) SEM of sample about $80 \mu \mathrm{m}$ depth.
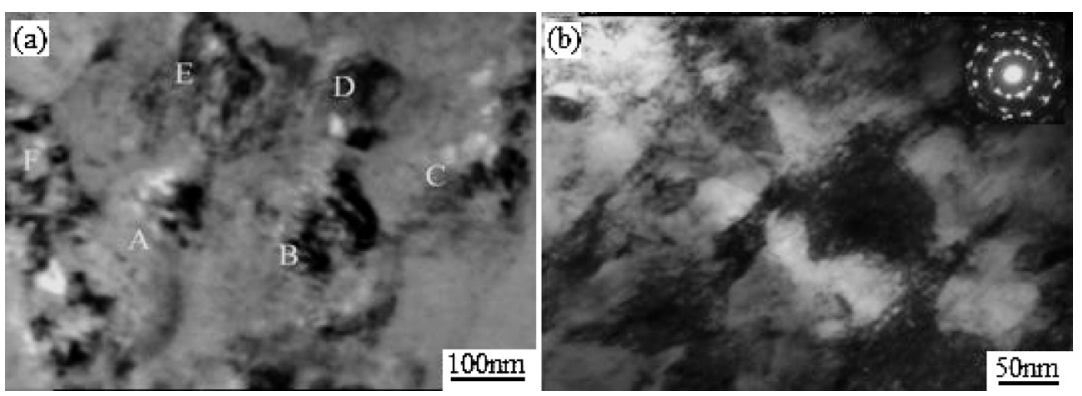

Fig. 6. TEM morphology of the layer $50 \mu \mathrm{m}$ from the topmost treated surface. (a) Formation of subgrains in twin by dislocation slip; (b) formation of nanograins in twin lamellar by dislocation walls. 
A, B, C, D, E and F are subgrains. In Fig. 6(b), the nanograins with below $100 \mathrm{~nm}$ were produced by high density dislocation walls (DDWs) induced by deformation, the corresponding selected area electron diffraction (SAED) pattern shows these nanograins have nearly random crystallographic orientation.

\section{Discussion}

Some researches shown, in the course of surface selfnanocrystallization, the refinement mechanism of coarse grains in metals materials depend strongly on the lattice structure and the stacking fault energy (SFE). ${ }^{1)}$ For example, in the bcc Fe with high SFE (about $200 \mathrm{~mJ} / \mathrm{m}^{2}$ ), coarse grains were divided into nanograins principally by dislocation walls and tangles; in the fcc $\mathrm{Cu}$ with medium SFE (about $78 \mathrm{~mJ} / \mathrm{m}^{2}$ ), coarse grains are refined into nanograins by dislocation movement and mechanical twinning; while in the fcc austenite AISI304 stainless steel with low SFE (about $17 \mathrm{~mJ} / \mathrm{m}^{2}$ ), mechanical twinning divided mostly coarse grians into nanograins. Recently years, literatures ${ }^{17-19)}$ have reported the grain refinement mechanisms of the pure Co (with a low SFE $27 \pm 4 \mathrm{~mJ} / \mathrm{m}^{2}$ ), Ti (with a rather high SFE $>300 \mathrm{~mJ} / \mathrm{m}^{2}$ ) and AZ91D (with SFE $60-78 \mathrm{~mJ} / \mathrm{m}^{2}$ ), notwithstanding the very large difference of SFEs for those hcp metals, the subdivision mechanism of grains in three metals all is that twinning deformation transformed coarse grains into nanograins at low strain, which illustrates that twinning might be a common deformation manner for metals with hep structure.

In the paper, based on the prior microstructure feature observations at various depths in the HESP samples, the plastic deformation layer on the ends of TA17 alloy can be partitioned into onset of twins, transition layer and the nanocrystalline layer, which will be convenient for probing into the grain refinement of TA17 alloy during the HESP.

\subsection{Onset of Twins}

In our work, after treated for TA17 by means of HESP, in the deformation zone approaching to the matrix (about $230 \mu \mathrm{m}$ ), merely single system twins were produced only in a small quantity coarse grains (as shown in Fig. 2 and Fig. 5(a)). In the zone, the stress and strain rate are low level because of being far away treated surface, single-system twinning deformation can be generated only in some grains whose orientations are favorable to deformation, the twin density is low. It is well known five independent slip systems are necessary for polycrystalline materials to undergo homogeneous plastic deformation, however, only four independent slip systems are available in hop titanium, and twinning is necessary in order to maintain the necessary deformation capability. The twinning planes in titanium are $\{10 \overline{1} 2\},\{11 \overline{1} 2\},\{11 \overline{2} 2\}$ and $\{10 \overline{1} 1\}$ depending on the temperature and deformation conditions. ${ }^{20)}$ Chichili $\mathrm{DR}^{21)}$ held that during the plastic deformation of titanium at ambient temperature, deformation twinning occurs first and accounts for less than $15 \%$ of the total plastic strain. Our observations are consistent with the literature. At low level of stress and strain rate, single-system twinning deformation is onset stage of grain refinement in surface selfnanocrystallization.

\subsection{Transition Layer}

In transition layer (about $60-150 \mu \mathrm{m}$ ), with the decreasing of depth to treated surface and the increasing of stress and strain rate, more and more grains orientation are favorable to twinning deformation in the course of HESP. A great of fine parallel lamellae were formed, the density of twin lamellae is higher than that in the zone of onset of twins, and twins intersection because of multi-system twinning deformatio exsit in some grains (as shown in Figs. 5(b) and 5(c)). In some places, the fine lamellar structure has virtually disappeared and has been converted into submicronic polygonal grains. Hence as the strain increases, the further formation of twins will reduce the scale of the microstructure very rapidly (as shown in Fig. 5(d). NematNasser $\mathrm{S}$ held that the dislocation activity will then predominate and the presence of a large number of twins and their intersection will hinder their movement as the strain increasing to a certain level. As a result, a high dislocation density occurs at twin boundaries in pure titanium. ${ }^{22)}$ In the work, as deformation twinning ceases to operate at moderate strain, an increasing dislocation density is observed which gives rise to the formation of lamellae leading to small misorientations subgrains (as shown in Fig. 6(a)). In addition to, it has been shown that the deformation mode of pure titanium, twinning or slip, depends very much on the crystallographic texture of the material. ${ }^{18)}$ In our work, the used TA17 near titanium alloy hot rolled bars were annealed for $3 \mathrm{~h}$ at $1023 \mathrm{~K}$ completely in a vacuum furnace, and the structures were formed homogeneous coarse equiaxial $\alpha$ grains. Therefore, there is no preferred orientation in samples which means that the relative activities of twinning and slip that have been observed do not result from the crystallographic texture. In the transition layer, microstructure feature is high density twin lamellae and submicronic grains resulted from multi-system twinning deformation.

\subsection{Nanogrians Layer}

In the top surface of treated samples, with further increasing stress and strain rate, multiple slip systems were generated and accumulated in a twin lamella, which leaded to the increasing of dislocation density and decreasing of space between dislocations. The dislocations were rearranged and formed dislocation walls in order to minimize the total system energy. Consequently, those dislocation walls transformed fine submicronic grains into small misorientation subgrains under a certain level of strain, and small misorientation subgrains were converted large misorientations exquiaxial fine nanograins by dislocation activity (as shown in Fig. 6(b)). At last, nanograins with $35 \pm 5 \mathrm{~nm}$ were achieved on the top surface by HESP treatment.

Based on the prior discussion, it can be deducted that the strain rate is very critical for refinement of coarse grains during HESP. In total deformation layer, as decreasing of depth to top surface the strain rate is increasing, twin systems are raising, dislocation density is more large. Finally equiaxed nanograins with random orientation were formed under the combination effects of heavy strain rate and multidirectional loads. However, the nanograins can not be refined infinitely in SNNC processing, the reason might be 
that new DDWs and/or DTs could not be generated inside fined grains due to the balance between dislocation multiplication and annihilation at the certain strain rate. ${ }^{9)}$

Besides, Zhu assumed that a recrystallization process may play a role in nanograins formation during the SMAT, ${ }^{18)}$ recrystallization can be considered as dynamic since it occurs during the HESP process. Derby considered that original grains structure are broken into nanograins according to mechanisms: nucleation and the growth of recrystallized grains in a deformed material (classical recrystallization) and the formation of recrystallization by the gradual rotation of subgrains (rotation recrystallization). ${ }^{23)}$ According to the literature, nucleation and growth of recrystallized nuclei occur as a result of annealing after rolling or swaging of pure titanium at $400-600^{\circ} \mathrm{C}{ }^{24)}$ Under severe plastic deformation conditions, such as torsional straining, there crystallization temperature is reduced to about $300^{\circ} \mathrm{C}^{25)}$ As for TA17 near $\alpha$ titanium alloy, a certain amount of heating may occur on the top treated surface during the HESP, but the top temperature is below $100^{\circ} \mathrm{C}$. TEM examination did not show any evidence of nucleation and growth mechanism for nanograins but clearly indicate the importance of grain boundaries rotation in microstructure development. It is therefore suggested that rotation recrystallization may play a major role in the final grain refinement mechanism during HESP.

\section{Conclusion}

(1) As for the TA17 near $\alpha$ titanium alloy after HESP treatment, a plastic deformation layer with maximum thickness of about $230 \mu \mathrm{m}$ was achieved. within $50 \mu \mathrm{m}$ to the treated surface coarse grains were transformed into equiaxial nanograins with an average size of $35 \pm 5 \mathrm{~nm}$, and on the top surface, the microhardness values are near twice that of the coarse-grained matrix.

(2) In the surface self-nanocrystallization of the TA17, the stress and strain rate are key factor for refinement of grains. Under low strain rate, single-system twinning deformation divides the coarse grains into twin lamellae; twin lamellae were transformed into submicron grains at medium strain rate by multi-system twinning deformation; submicron grains were further breakdown into randomly oriented equiaxial nanograins resulted from DDWs under high strain rate level.

\section{Acknowledgements}

The author acknowledges financial support from the National Science Foundation of China (No. 50675234). The author acknowledges financial support from the Great Equipments Opening Foundation of Chongqing University.

\section{REFERENCES}

1) K. Lu and J. Lu: Mater. Sci. Eng. A, 375-377 (2004), 38.

2) D. G. Morris: Mechanical Behaviour of Nanostructured Materials, Trans. Tech. Publications Ltd., Germany, (1998), 70.

3) Z. B. Wang, N. R. Tao, W. P. Tong, J. Lu and K. Lu: Acta Mater, 51 (2003), 4319.

4) R. Birringer, H. Gleiter, H. P. Klein and P. Marquardt: Phys. Lett. A, 102 (1984), 365.

5) K. Lu and J. T. Wang: Mater Sci. Eng., 97 (1988), 399.

6) U. Erb, A. M. El-Sherik, G. Palumbo and K. T. Aust: Nanostruct. Mater, 2 (1993), 383.

7) R. Z. Valiev, A. V. Korznikov and R. R. Mulyukov: Mater Sci. Eng. A, 168 (1993), 141.

8) K. Lu and J. Lu: Chinese Patent, No. 01122980, 2 (2001); French Patent, FR2812284 (2001).

9) N. R. Tao, Z. B. Wang, W. P. Tong, M. L. Sui, J. Lu and K. Lu: Acta Mater, 50 (2002), 4603.

10) N. R. Tao, M. L. Sui, J. Lu and K. Lu: Nanostruct. Mater., 11 (1999), 433.

11) J. F. Gu, D. H. Bei, J. S. Pan, J. Lu and K. Lu: Mater Lett., 55 (2002), 340.

12) G. Liu, S. C. Wang, X. F. Lou, J. Lu and K. Lu: Scr. Mater, 44 (2001), 1791.

13) Z. B. Wang and N. R. Tao: Mater. Sci. Eng. A, $\mathbf{A 3 5 2}$ (2003), 144.

14) G. Liu, J. Lu and K. Lu: Mater. Sci. Eng. A, A286 (2000), 91.

15) K. Y. Zhu, A. Vassel, F. Brisset, K. Lu and J. Lu: Acta Mater, 52 (2004), 4101.

16) Y. S. Zhang, Z. Han, K. Wang and K. Lu: Wear, 260 (2006), 942.

17) $\mathrm{X}$. Wu, N. Tao, Y. Hong, G. Liu, B. Xu and J. Lu et al.: Acta Mater., 53 (2005), 681.

18) K. Y. Zhu, A. Vassel, F. Brisset, K. Lu and J. Lu: Acta Mater, 52 (2004), 4101.

19) H. Q. Sun, Y. N. Shi, M. X. Zhang and K. Lu: Acta Mater, 55 (2007), 975.

20) N. Munroe, X. Tan and H. Gu: Scr. Mater, 37 (1997), 1089.

21) D. R. Chichili, K. T. Ramesh and K. J. Hemker: Acta Mater, 46 (1998), 1025.

22) S. Nemat-Nasser, W. G. Guo and J. Y. Cheng: Acta Mater, 47 (1999), 3705.

$23)$ B. Derby: Acta Metall. Mater, 39 (1991), 955.

24) S. Nourbakhsh, M. Blicharski and J. Nutting: Titanium Science and Technology, DGM, Germany, (1984), 1729.

25) A. A. Popov, I. Y. Pyshmintsev, S. L. Demakov, A. G. Illarionov, T. C. Lowe and A. V. Sergeyeva: Scr. Mater, 36 (1997), 1383. 